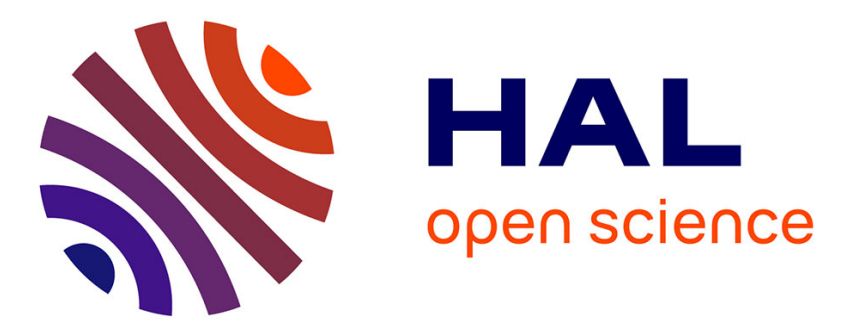

\title{
Influence of Floating Structures on Tide-and Wind-Driven Hydrodynamics of a Highly Populated Marina
}

\author{
Jean-Rémy Huguet, Isabelle Brenon, Thibault Coulombier
}

\section{To cite this version:}

Jean-Rémy Huguet, Isabelle Brenon, Thibault Coulombier. Influence of Floating Structures on Tideand Wind-Driven Hydrodynamics of a Highly Populated Marina. Journal of Waterway, Port, Coastal, and Ocean Engineering, 2020, 10.1061/(ASCE)WW.1943-5460.0000549 . hal-02437509

HAL Id: hal-02437509

https: / hal-univ-rochelle.archives-ouvertes.fr/hal-02437509

Submitted on 14 Jan 2020

HAL is a multi-disciplinary open access archive for the deposit and dissemination of scientific research documents, whether they are published or not. The documents may come from teaching and research institutions in France or abroad, or from public or private research centers.
L'archive ouverte pluridisciplinaire HAL, est destinée au dépôt et à la diffusion de documents scientifiques de niveau recherche, publiés ou non, émanant des établissements d'enseignement et de recherche français ou étrangers, des laboratoires publics ou privés. 


\section{Influence of floating structures on the tide and wind-driven hydrodynamics}

\section{2 of a highly populated marina}

Jean-Rémy Huguet ${ }^{1}$, Isabelle Brenon ${ }^{2}$ and Thibault Coulombier ${ }^{3}$

${ }^{1}$ PhD student at UMR 7266 LIENSs, CNRS-Université de La Rochelle, 2 rue Olympe de Gouges, 17000 La Rochelle, France (corresponding author). E-mail: jean-remy.huguet@univ-lr.fr

${ }^{2}$ Associate professor at UMR 7266 LIENSs, CNRS-Université de La Rochelle, 2 rue Olympe de Gouges, 17000 La Rochelle, France. E-mail: isabelle.brenon@univ-lr.fr

${ }^{3}$ Research engineer at UMR 7266 LIENSs, CNRS-Université de La Rochelle, 2 rue Olympe de Gouges, 17000 La Rochelle, France. E-mail: thibault.coulombier@univ-lr.fr

Abstract: Harbor siltation is a problem that will exist as long as harbors exist and it is intrinsically linked to their primary function - providing shelter for anchorage and operative conditions for loading/unloading ships. In these semi-enclosed basins, flow characteristics are one of the main factors influencing siltation and water quality. One of the largest recreational ports of Europe, La Rochelle Marina (southwestern France), is not spared by siltation, which requires serious dredging operations during a major part of the year. In this context, a three dimensional model (TELEMAC 3D) has been used to investigate its hydrodynamics. Using a simplified approach, floating structures were implemented in the model. Comparison with observations has demonstrated the need to consider these structures in our study. They significantly reduce velocity in the inner parts of the marina and concentrate current on access channels. Numerical results also highlight the joint role of the macrotidal regime and wind stress in the movement of water masses and their residual circulation.

Author keywords: Hydrodynamics; Marina; Numerical modeling; Floating structures; Residual flux. 


\section{Introduction}

Similar to every area protected from the combined action of waves and marine currents, ports suffer siltation (Winterwep, 2005). This siltation depends on environmental parameters, such as the local tidal range and wave climate, meteorological conditions, and river input. Port siltation is also influenced by the planform geometry and basin state of enclosure (Falconer, 1992; Nece, 1984). Furthermore, these areas are used extensively, and thus require particular attention in terms of currentology, sediment deposition and water quality.

The increasing concern of planners and designers for hydro-environmental problems relating to semienclosed environments fosters development of an operational modeling system. However, they are difficult to model accurately due to their composite geometry (quays, channels, docks, etc.) affecting the circulation of water, both occasionally and permanently. Indeed, docks and boats floating in the port could also play a substantial role, by attenuating surface currents with friction and by decreasing wind action. Many modeling studies have been carried out to investigate environmental and engineering problems at the harbor scale. For instance, SanchezArcilla et al. 2002) correlated the capacity to flush to hydrodynamics and Murphy et al. (2012) characterized dead zone mixing processes in several marina configurations. In this paper, we focus on the effect of floating structures. Indeed, although some studies have investigated the effect of currents and/or waves on floating docks (Tajali et al., 2008; Ghadimi et al., 2014), few have investigated the influence of floating bodies on water circulation (Ligier, 2016).

The study site, La Rochelle Marina, located in southwestern France, is currently considered the largest marina on the European Atlantic coast. Recently, in order to satisfy continued growth of recreational sailing, the marina has been expanded after three years of construction and transformation. The marina is not spared by siltation and has to spend $10 \%$ of its total budget to dredge around $200,000 \mathrm{~m} 3$ of cohesive sediment each year. Thus, characterizing hydrodynamics and sediment flux is of key importance in this area where annual sediment deposition can overpass $50 \mathrm{~cm}$ in some basins (Pers. Com. La Rochelle Marina).

This study aims to investigate the influence of floating structures on marina hydrodynamics by threedimensional numerical simulation. In the next two sections, we describe the area and methods used in the model to perform realistic numerical simulations of water circulation at several temporal and spatial scales. Numerical results are then compared against in situ observations before analyzing the influence of floating structures at the marina scale. Their implementation is finally discussed before concluding. 


\section{Description of the study site}

\section{La Rochelle Marina}

The study area is a 50 ha recreational port located along the French Atlantic Coast, in the central part of the Bay of Biscay. It is located in the landward part of the Pertuis d'Antioche embayment, corresponding to a drowned river valley segment (Chaumillon and Weber, 2006) and characterized by silty to sandy-silty bottoms. This shallow water coastal area, protected from the Atlantic Ocean by the Ré and Oléron islands, is characterized by a $44 \mathrm{~m}$ deep trench and many tidal flats (Fig. 1). Moreover, it is an urban marina with the city of La Rochelle displaying a land area of $2843 \mathrm{~km}^{2}$ and a population of 80,000 inhabitants.

Created in 1972, La Rochelle Marina has been the largest marina along the Atlantic coast, since its expansion in 2014. This $900 \mathrm{~m}$-long and $820 \mathrm{~m}$-wide semi enclosed area is divided into 3 basins totaling 4500 moorings, distributed along $15 \mathrm{~km}$ of floating docks. The southwestern (SW) basin is larger, with 22 ha, whereas the western (W) and the northeastern (NE) basins, contain 17 and 15 ha, respectively. The marina is accessible by a $110 \mathrm{~m}$ wide main entrance, and the expansion basin has two openings: $150 \mathrm{~m}$ wide to the northeast and $64 \mathrm{~m}$ wide to the southeast. To mitigate siltation, the marina requires recurring dredging of its basins, 8 months a year, so that the whole marina is dredged every 3 years.

\section{Coastal area hydrodynamics}

The coastal area is considered a mixed, wave and tide-dominated estuary (Chaumillon and Weber, 2006). The tidal schedule is semidiurnal and the tidal range varies from $2 \mathrm{~m}$ during neap tides to more than $6 \mathrm{~m}$ during spring tides, where strong tidal currents can locally reach up $2 \mathrm{~m} . \mathrm{s}^{-1}$. Tides are dominated by M2, and its amplitude grows to more than $1.8 \mathrm{~m}$ in the inner part of the estuaries due to resonance and shoaling (Bertin et al., 2012). Furthermore, the quarter-diurnal tidal constituents (M4, MS4 and MN4) are strongly amplified shoreward, because of resonance occurring on the Bay of Biscay shelf (Le Cann, 1990; Toublanc, 2015). The yearly average significant wave height is approximately $1.5 \mathrm{~m}$ with periods between $8 \mathrm{~s}$ and $12 \mathrm{~s}$, whereas wave height can be larger than $8 \mathrm{~m}$ during winter storms in front of the Pertuis d'Antioche (Bertin et al., 2015). However, refraction, diffraction and bottom friction in the inner part of the estuaries drastically decrease wave energy. Storm waves and strong tidal currents are considered the main drivers of resuspension and contribute to a high level of turbidity at the scale of the bay (Le Hir et al., 2010). 


\section{Numerical modeling}

\section{General description of the modeling system}

In this study, we employed the TELEMAC 3D model (Hervouet, 2007), part of the open-source hydrodynamic suite of TELEMAC system (Hervouet, 2000) adapted to free-surface flow modeling.

TELEMAC 3D is used and validated in a wide range of studies (Villaret et al., 2013; Bedri et al., 2011; Kopmann and Markofsky, 2000; Cornett et al., 2010) by solving the following 3D Navier-Stokes equations:

$$
\operatorname{div}(\vec{U})=0
$$

$$
\begin{aligned}
& \frac{\partial U}{\partial t}+\vec{U} \cdot \overrightarrow{\operatorname{grad}}(U)=\frac{-1}{\rho_{0}} \frac{\partial p}{\partial x}+\operatorname{div}\left(v_{t} \overrightarrow{\operatorname{grad}}(U)\right)+f_{x} \\
& \frac{\partial V}{\partial t}+\vec{U} \cdot \overrightarrow{\operatorname{grad}}(V)=\frac{-1}{\rho_{0}} \frac{\partial p}{\partial y}+\operatorname{div}\left(v_{t} \overrightarrow{\operatorname{grad}}(V)\right)+f_{y} \\
& \frac{\partial W}{\partial t}+\vec{U} \cdot \overrightarrow{\operatorname{grad}}(W)=\frac{-1}{\rho_{0}} \frac{\partial p}{\partial z}+\operatorname{div}\left(v_{t} \overrightarrow{\operatorname{grad}}(W)\right)+f_{z}
\end{aligned}
$$

where $\mathrm{t}$ is the time $(s) ; x, y$, and $z$ the sigma-coordinates; $U, V, W$ are the velocity components in the $x, y$, and $z$ directions $\left(m . s^{-1}\right) ; \rho_{0}$ is the reference density $\left(\mathrm{kg} . \mathrm{m}^{-3}\right) ; p$ is the pressure term $\left(N . \mathrm{m}^{-2}\right) ; v_{t}$ is the turbulent diffusion coefficients $\left(m^{2} . s^{-1}\right)$ and $f_{x}, f_{y}$, and $f_{z}$ are the source and sink terms $\left(m . s^{-2}\right)$.

Turbulence is modeled with k- $\varepsilon$ model and the non-hydrostatic mode is used to perform simulations over an unstructured grid (Fig. 2), from the regional (embayment) to local scale (marina), and at a large range of temporal scales. Mesh is varying in function of the bathymetry and the area of interest, from $2 \mathrm{~km}$ offshore to almost $5 \mathrm{~m}$ in the whole marina. Bottomstress is computed through the widely used Chézy parameterization (Rijn, 1984; Weitz et al., 1992; Deng et al., 2002; Nicolle and Karpytchev, 2007). The bottom frictional stress $\tau$ is then represented by the quadratic relationship:

$$
\tau=\rho \frac{g U^{2}}{C^{2}}
$$

where $U$ is the vertically averaged velocity; $\rho$ the water density $\left(k g . m^{-3}\right)$; g the gravity acceleration $\left(m . s^{-2}\right)$ and $\mathrm{C}$ is the Chézy friction coefficient $\left(m^{0.5} \cdot s^{-1}\right)$. We set spatially variable friction in the model by prescribing different value of Chézy coefficient depending on the bottom nature. Following the methodology in Nicolle (2006) concerning the Chézy parametrization in the Pertuis, we used a $100 \mathrm{~m}^{0.5} \cdot \mathrm{s}^{-1}$ coefficient for mud, $80 \mathrm{~m}^{0.5} \cdot \mathrm{s}^{-1}$ for fine sand, $60 \mathrm{~m}^{0.5} . \mathrm{s}^{-1}$ for sand and $45 \mathrm{~m}^{0.5} . \mathrm{s}^{-1}$ for rocky bottoms.

The semi-implicit Galerkin finite element method is used to solve continuity and momentum equations. An Eulerian-Lagrangian treatment of advective terms and a semi-implicit method insures numerical stability, even with large time steps. The treatment of tidal flats ensured the conservation of mass and momentum. (Hervouet, 
2015; Hervouet, 2011). Finally, wind effects are modeled as a two-dimensional condition at the water surface through the equation:

$$
v_{H} \frac{\partial \overrightarrow{U_{H}}}{\partial \eta}=\frac{\rho_{a}}{\rho} a_{w} \vec{w}\|\vec{w}\|
$$

Where $\vec{w}$ is the wind velocity $10 \mathrm{~m}$ above the water surface $\left(m \cdot s^{-1}\right) ; \overrightarrow{U_{H}}$ is the horizontal velocity of the water surface $\left(m \cdot s^{-1}\right) ; \eta$ is the elevation $(m) ; \rho_{a}$ is the air density $\left(\mathrm{kg} \cdot \mathrm{m}^{-3}\right)$; and $a_{w}$ the wind stress coefficient defined by Flather, (1976).

\section{Model implementation}

The modeled area is $35 \mathrm{~km}$ wide and $100 \mathrm{~km}$ long and is discretized on a 41,000 node unstructured grid, with resolution from $2 \mathrm{~km}$ offshore to nearly $5 \mathrm{~m}$ inside the marina. In this study, the coordinate system is converted into a topography-following coordinate system via a sigma transformation. A sensitivity analysis has revealed that the use of 8 vertical sigma levels was optimal/sufficient to reproduce three-dimensional circulation in the marina. These sigma levels are treated with the Arbitraty Lagrangian-Eulerian method (Donea, 1982), and lead to 320,000 nodes. We use bathymetry from the French Navy (hereafter SHOM) and benefit from a twice per year single beam survey in the marina. Then, the topography of intertidal areas are determined using LiDAR survey, acquired in 2010 (LITTO3D, French National Geographic Institute and SHOM).

Four kinds of boundary conditions are used in the model. Firstly, the coastline, that corresponds to a solid boundary, where the friction governs the relation between velocity and its gradient. The bottom also plays the role of a boundary wall where a spatially variable Chézy friction is imposed. Along, its open boundary, the model is forced by 34 astronomical tidal constituents (O1, K1, P1, Q1, M2, S2, N2, K2, 2N2, MU2, NU2, L2, T2, M3, M4, MN4, MS4, M6, M8, EPS2, MSF, MSQM, MM, SSA, SA, S4, MKS2, MF, LA2, J1, N4, MTM, R2, and S1), obtained by linear interpolation from the global tide model FES2014 (Finite Element Solution - v.2014). Then, the surface boundary of the model is forced with space and time variable sea-level atmospheric pressures and 10 $\mathrm{m}$ winds from the CFSR (The Climate Forecast System Reanalysis provided by the National Center for Environmental Prediction), with spatial and temporal resolution of $0.5^{\circ}$ and $1 \mathrm{~h}$. Atmospheric forcing is set over the whole domain with hourly sea-level atmospheric pressure and $10 \mathrm{~m}$ wind speed and direction originating from the Climate Forecast System Reanalysis (CFSR) provided by the National Center for Environmental Prediction (NCEP). The hydrodynamic time step is set to $5 \mathrm{~s}$ after a sensitivity analysis. Observations (CREOCEAN, unpublished data, 2004) showed that the marina is sheltered enough from ocean waves and is more sensitive to the development of small wind-generated waves, in particular during storms where maximum wave height approach $15 \mathrm{~cm}$. Thus, in the framework of this study, we did not simulate wave propagation. 


\section{Implementation of the floating structures in the model}

Field trips involving the deployment of surface drifting buoys inside the marina have shown the complexity of water mass circulation. Steady currents and local eddies were visible at the channel entrance during the deployment; some buoys experienced stagnant conditions $\left(<0.001 \mathrm{~m} . \mathrm{s}^{-1}\right)$ while others were moved rapidly in the inner part of the marina by high intensity currents $\left(>0.5 \mathrm{~m} \cdot \mathrm{s}^{-1}\right)$. Small-scale eddies and steady currents were also noticed near floating structures that, combined with the high density of docks and moorings in the marina, could have a significant impact on the velocity field in the inner part of the marina. Indeed, all the floating docks and moored boats represent more than a third of the total surface of this semi-enclosed area. Flows near floating obstacles were studied through numerical modeling and lab experiments (Tajali et al. 2008, Drobyshevski, 2004). However, they are poorly understood because of the complexity of three-dimensional unsteady currents and sensitivity to a large number of parameters (Martinuzzi and Tropea, 1993; Baker, 1980). To evaluate the effect of floating docks and moorings on the water mass circulation in the inner part of the marina, we conducted a modeling study with the presence of floating structures. Two methods are available with TELEMAC- 3D. The first is to locally increase the atmospheric pressure gradient to lower the free surface and apply surface friction according to the Nikuradse friction law. As it would have been computationally expensive to apply this method, we chose to implement a second method. This method consists of applying local head losses at each involved computational node. The head losses correspond to friction loss terms at the free surface that represent the flow resistance created by a rough surface in contact with the fluid. This method has been implemented in an implicit way as a source term in the three-dimensional momentum equations (2) via the following expressions:

$$
\begin{aligned}
& f_{x}=S 1 U . U \\
& f_{y}=S 1 V \cdot V \\
& f_{w}=S 1 W . W
\end{aligned}
$$

With $f_{x}, f_{y}$, and $f_{z}$ the source terms in three directions $\left(m . s^{-2}\right)$ included in the 3D momentum equations; $U, V$, and $W$ are the three velocity components $\left(m . s^{-1}\right)$ and $S 1 U, S 1 V, S 1 W$ the intermediate terms $\left(s^{-1}\right)$ defined by:

$$
\begin{aligned}
& S 1 U=C .\|U\| \\
& S 1 V=C .\|V\| \\
& S 1 W=C .\|W\|
\end{aligned}
$$

With $C$ the coefficient corresponding to a friction coefficient $\left(m^{-1}\right)$. 
The nodes involved in the model correspond to the position of floating docks, whose draught varies between $0.5 \mathrm{~m}$ and $2 \mathrm{~m}$ with a mean value of $1.18 \mathrm{~m}$ for the whole marina. We independently integrated the two kinds of structures in the model. A third of the marina surface nodes were affected by this implementation. In term of CPU time, simulations with floating structures requires about one-quarter higher CPU time than basic simulations. Using forty cores of a supercomputer, it approximately leads to a total of 20 hours to simulate 15 days with 8 sigma layers.

This method is relatively sensitive to mesh resolution, which has been considered in our numerical simulations. A sensitivity analysis was performed to calibrate $C$ in agreement with field observations. The calibration of $C$ was performed with one measurement point (visible in validation section). The best $C$ coefficient was found to be $0.6 \mathrm{~m}^{-1}$ for mooring boats and $0.5 \mathrm{~m}^{-1}$ for floating docks. During the calibration process, a large number of $C$ coefficient was tested, ranging from 0.1 to $2 \mathrm{~m}^{-1}$ and the modeled results were found consistent with the observations for a $C$ coefficient ranging from 0.3 to $0.8 \mathrm{~m}^{-1}$.

\section{Validation}

\section{Water levels}

The model was calibrated and validated using water level measurements taken offshore and inside the marina (the white stars with red borders in Fig. 1). La Pallice data (radar) were collected through the REFMAR portal (data.shom.fr/), and water levels in the marina (pressure sensors) were acquired in March 2017. The comparison between numerical results and 10-minute continuous time series measurements (Fig. 3) shows a Root Mean Squared Error (RMSE) of $0.18 \mathrm{~m}$ for La Pallice with $0.17 \mathrm{~m}$ average for the four stations in La Rochelle Marina (Table 1). Globally, water levels are very well reproduced by the model at the five stations with errors about $3-4 \%$, once normalized by the mean local tidal range. Offshore, at the other stations (Fig. 1), water levels are also well reproduced with the same level of error (Table 1). It is also important to note that there are few differences in the water level signal between simulations with and without floating structures.

\section{Current in the channel entrance}

Three ADCP current-meters were deployed in 2014 by the CREOCEAN engineering company, after the marina expansion (black stars 1, 2, 3 in Fig. 1). In this section, we display vertical profiles of current at the marina entrance (black star 1 in Fig. 1) obtained during spring tides where the mean tidal range was approximately 6 meters. Observations revealed a strong distortion of the tide at the entrance, with a strong tidal flood that is not compensated, in terms of intensity, during ebb; during spring tides, current can overpass $1.5 \mathrm{~m} . \mathrm{s}^{-1}$ at the 
beginning of flood tide and reach $0.8 \mathrm{~m} . \mathrm{s}^{-1}$ at the end of ebb tide. Fig. 4 displays the comparison between numerical results obtained with floating structures and the observations. Surface velocity was observed $0.5 \mathrm{~m}$ below the free surface and bottom velocity was observed $1.5 \mathrm{~m}$ above the bottom. The model faithfully reproduces this behavior, with a very good reproduction of the peak flow of the ebb and flood tides. Moreover, speeds are relatively in phase, from the bottom to the surface and the main directions (north at flood and south at ebb) are well reproduced. Table 2 summarizes the differences between numerical results and in situ observations of current both in terms of intensity and direction. RMSE is approximately $0.07 \mathrm{~m} . \mathrm{s}^{-1}$ and $51.3^{\circ}$ for intensity and direction, respectively. The model underestimates velocity by less than $2 \%$, mainly due to underestimating peak flows. For a simulation without floating structures, the current behavior is similar, with a slight intensity decrease during peak flows (approximately $0.05 \mathrm{~m} . \mathrm{s}^{-1}$ ).

\section{Currents in the vicinity of the marina}

To better understand the dynamics of the marina, an up-looking ADCP current-profiler (Aquadopp Profiler, $2 \mathrm{Mhz}, 20 \mathrm{~cm}$ cells) was deployed just below floating docks (black star 4 in Fig. 1). Data acquisition displayed vertical accuracy of approximately $0.008 \mathrm{~m} \cdot \mathrm{s}^{-1}$ and horizontal accuracy of approximately 0.003 $m . s^{-1}$. The aim of this instrumentation was not only to understand how currents are modified by the presence of floating docks but also to calibrate and compare our modeling system in the inner parts of the marina. The 5day measurement occurred from April to May 2018, with a relatively important tidal range (4 to 5 meters) and calm weather (mean wind speed approximately $5 \mathrm{~m} \cdot \mathrm{s}^{-1}$ ). Fig. 5 shows the comparison between simulated and measured velocity for one day. Measured velocity displays the maximum current during the flood 2 hours after low tide but, contrary to the channel entrance, the water column is stratified. Indeed, the velocity is stronger at the bottom (Fig. 5A). Then, floating structures appear to have a role in the attenuation of surface velocity. A preliminary calibration of the friction loss coefficient has been carried out to fit the model results to measurements in the inner part of the marina. The corresponding results for the period of acquisition are shown in Fig. 5B, and the simulations without floating structures are shown at the bottom (Fig. 5C). The simulation without floating structures overestimates the velocity by a factor of two during peak flow. No stratification is found in the water column. In terms of current intensity, current seems quasi-homogeneous as at the channel entrance (Fig. 4). The simulation with floating structures, better reproduces the measured velocity order of magnitude of approximately $0.07 \mathrm{~m} . \mathrm{s}^{-1}$ during peak flow. Moreover, the stratification is well represented and fits the measurements. There is still some bias compared to reality: the attenuation along the vertical axis is not 

is provided in term of intensity and directions. Directions are more dispersed and less channeled than in the channel entrance (Fig 4) and their reproduction is slightly worse with a 75,8 $\mathrm{RMSE}$ and $-12.5^{\circ}$ bias. However, the main directions are preserved with the model with FS compared to the model without FS that generates more channelized directions of different direction. Comparison of surface velocity (Fig. 6), observed $0.5 \mathrm{~m}$ below the free surface, confirms the overestimation by the simulation without floating structures. Between measurements and numerical results, a $0.064 \mathrm{~m} . \mathrm{s}^{-1} \mathrm{RMSE}$ is reached, with maximum error of approximately $0.10 \mathrm{~m} . \mathrm{s}^{-1}$. With floating structures in the simulation, the peak flow occurred in phase with measurements, and accurately fit the magnitude of intensity. The RMSE is much better, with $0.012 \mathrm{~m} . \mathrm{s}^{-1}$ accuracy for a maximum error

\section{Results}

approximately $0.025 \mathrm{~m} . \mathrm{s}^{-1}$ and an average overestimation of $0.5 \%$.

\section{Tidal circulation in the marina}

Hydrodynamic simulations were performed under tidal and meteorological forcings. Even if wind forcing can influence velocity fields, considering the relatively shallow depths of the water column, numerical modeling suggests a major impact for tide on the currents. Then, contrary to the Bilbao (Grifoll et al., 2009) and Genoa ports (Cutroneo et al., 2017), density-driven circulation is considered nonexistent in La Rochelle marina. Indeed, there is no freshwater influence except during occasional heavy rainfall. Therefore, in this section, the modeled results are analyzed assuming that the tide is the main factor controlling the water circulation pattern.

The main circulation patterns are shown in Fig. 7. The depth-averaged velocity displayed was computed for a spring tide (tidal range $=6 \mathrm{~m}$ ), with and without the implementation of floating structures in the model. The maximum velocity in the marina is located in the channel entrance at the end of the ebb and beginning of the flood, when the section is the lowest. The behavior of water bodies during flood and ebb is very different. A strong flood enters the marina by the main entrance with maximum amplitude up to $1.7 \mathrm{~m} . \mathrm{s}^{-1}, 1$ hour after low tide, whereas the ebb is two times lower in intensity and mainly focused on the channel entrance. At the end of ebb tide the current is rapidly reversed by the flood at the channel entrance. The opposition between these two flows leads to complex current in terms of direction and intensity. Current presents a large range of intensity substantially influenced by basin geometry. For instance, a W basin displays stagnant water with velocity lower than 0.01 $m . s^{-1}$, reaching only $0.05 \mathrm{~m} . \mathrm{s}^{-1}$ at peak flow. During neap tide, where the tidal range is approximately $2 \mathrm{~m}$, the 
velocity decreases by a factor of two, but the same trend remains in the marina. The main changes occur during ebb with weak eddy reduction and lower water flux compared with spring tide.

At the entrance sections, there is an asymmetry in term of flood-ebb duration, which is inverse function of the tidal range. At the main entrance (section 1), during spring tides there is a $5 \mathrm{~h} 30 \mathrm{~min}-6 \mathrm{~h} 40$ min ratio against a $4 \mathrm{~h} 30 \mathrm{~min}-7 \mathrm{~h} 20$ min ratio during neap tides but fluxes at the entrances are globally enhanced during flood. The tidal asymmetry of the offshore area explains this asymmetry of flux between flood and ebb tide, as discussed earlier (Guo et al., 2018). The asymmetry can also result from signal distortion generated by the system geometry (quays, entrances sections) and bathymetry (Nece and richey 1972; Sztano and De Boer, 1995).

\section{Impact of floating structures on marina tidal circulation}

The main difference between the simulation with and without the floating structures concerns the flood. With FS, there is a faster velocity decrease and faster divide of the entering flood into two directions. Furthermore, the addition of floating structures reduces the development of eddies at the scale of each sub-basin (Fig. 7A and 7B). Once the stream enters the $\mathrm{W}$ and SE basins, we observe a strong decrease in eddy intensity in surface layers and a very strong reduction in the size and intensity of the eddies. During the ebb, water circulation is slightly noticeable in the inner part of the marina. Consequently, the impact of floating structures in the model is weak. Indeed, the main currents are located along the channel entrance, which appears to be slightly impacted by the presence of floating structures. During flood and ebb tide the maximum velocity along the channel entrance is slightly accentuated by floating structures (Table 3). The southern part of the W and SE basins are the most impacted by the attenuation of velocity, displaying large stagnant water areas (Fig. 7G and 7H) where intensity is lower than $0.01 \mathrm{~m} . \mathrm{s}^{-1}$ except during the flood where intensity can reach $0.05 \mathrm{~m} . \mathrm{s}^{-1}$.

Quantitatively, Table 3 reveals the impact of the implementation of floating structures on the velocity field of the marina. The effect is more significant during spring tides when currents are stronger. From neap to spring tides, in the $\mathrm{W}$ basin, velocity intensity was reduced from $8 \%$ to $28 \%$, respectively. In the SW basin, the velocity was reduced from $3 \%$ to $15 \%$, respectively, and in the NE basin, the main reductions were $10 \%$ and $65 \%$, respectively. However, the velocity decrease in the inner parts of the marina is compensated by velocity acceleration in other locations. The relatively higher velocity during ebb supports this assertion with the presence of floating bodies (Table 3).

The effect of floating structures increases towards the inner parts of basins. Their presence attenuates currents at the surface that consequently reduce the currentology of the inner parts of the marina. 
The wind regime in the area, and more globally in the whole Bay of Biscay, experiences a significant interannual variability (Dodet et al. (2010)), which is partly controlled by the North Atlantic Oscillation. The weakest winds, lower than $4 \mathrm{~m} . \mathrm{s}^{-1}$, occur $58 \%$ of the time, moderate winds, from 4 to $8 \mathrm{~m} . \mathrm{s}^{-1}$, occur $29 \%$ of the time and the strongest, from 8 to $16 \mathrm{~m} . \mathrm{s}^{-1}$, occur $12 \%$ of the time. Summer presents weak low-pressure system activity resulting in weak winds mostly originating northeasterly while the littoral is mainly dominated by thermic breezes from the north-west. During autumn, low-pressure systems cross the Atlantic Ocean, creating more energetic winds from south-west to west. These low-pressure systems are most active during winter, and they can potentially cross the French Atlantic coast where strong winds are often observed. These systems result in the predominance of four winds over the area of study: northwestern (22\% occurrence), western ( $21 \%$ occurrence), northeastern (19\% occurrence) and southern (14\% occurrence) winds.

To understand the role of the wind in the area, twelve specific cases were studied, corresponding to six atmospheric conditions (one without wind, four with an average $7.5 \mathrm{~m} . \mathrm{s}^{-1}$ wind from several directions, one with a strong $15 \mathrm{~m} . \mathrm{s}^{-1}$ wind from the west) linked with 2 tidal conditions (spring and neap tides). Residual flux (RF) was computed over five tidal cycles, at three different sections for every case. The first case corresponds to a situation with only tides; the four following are simulations of combined tide and wind forcing related to the four dominant area winds. These five cases were simulated for a spring tide with 6-meter tidal range and a neap tide with 2-meter tidal range. Three sections were defined in this study to compare residual flux (Fig. 8).

This study shows that the total RF in the marina is a general inflow mainly governed by section 3 . For neap and spring tides, the configuration is the same with an offshore RF at section 1 and 2 and an onshore RF at section 3. The only difference is that RF are significantly higher during spring tides. The presence of a west wind enhances the westward residual circulation established from section 3 to section 1. This residual dynamic is also conserved, but with less intensity, when the wind is northwest. With a northeast wind, this residual circulation is completely reversed and oriented from section 1 to section 3. RF for simulations with a southern wind is not presented in Fig. 8 because it is relatively unchanged compared with no-wind simulations. Depending on its direction, the wind has an anisotropic effect, which can be significant in particular during neap tides. Finally, it is important to notice that the absence of floating structures in the model does not noticeably affect the RF at the sections. 


\section{Assessment of the main drivers of circulation}

To more accurately investigate the influence of the water circulation-driving mechanisms, velocity depth average was computed with numerical modeling and analyzed for the 12 specific cases. The mean differences between states without and with wind stress, regardless of direction, range from $0.02 \mathrm{~m} . \mathrm{s}^{-1}$ to $0.01 \mathrm{~m} . \mathrm{s}^{-1}$ with maximum difference of approximately $0.70 \mathrm{~m} . \mathrm{s}^{-1}$ during the maximum flood/ebb tide. Table 4 reveals the mean velocity averaged over 5 tidal cycles for several wind directions. Large differences appear according to wind directions but, globally, wind decelerates water mass dynamics during spring tides and accelerates them during neap tides. For spring tides, only a $7.5 \mathrm{~m} . \mathrm{s}^{-1}$ south wind is able to increase the water circulation whereas other winds decrease circulation (up to $25 \%$ for an NE wind). During neap tides, the west, northwest and south winds increase velocity up to $34 \%$, whereas the northeast wind only increases it by $14 \%$. The behavior of water masses is consistent, first with the direction of tidal propagation in the bay for a northeast wind and second with the direction of channel entrance for a south wind. More generally, average winds have a significant influence on velocity mainly during neap tides. Strong events as $15 \mathrm{~m} . \mathrm{s}^{-1}$ west winds that occur frequently during winter in the area, can overpass the tidal forcing by increasing the neap tides velocity by more than $50 \%$. Finally, the results show that the significant influence of the wind follow the same trend with and without floating structures (Table 4). However, while their effect is similar during spring tides (a decrease of the mean velocity), the wind and the floating structures display an antagonistic effect during neap tides by increasing and decreasing the velocity, respectively.

\section{Discussion}

\section{Relevance of considering floating structures in the model}

Structures such as floating docks and breakwaters are often encountered in the modeling domain, but their effect is often neglected. This effect can be very complex to incorporate in some applications. Tsay and Liu (1983) and $\mathrm{Li}$ et al. (2005) proposed an approach to approximate the effect of floating structures in a $2 \mathrm{D}$ elliptic harbor wave model. However, a simplified approach has permitted us to simulate their effect on hydrodynamics. Indeed, comparison with observations has shown the necessity to implement floating structures in order to better fit the reality. Even if floating structures have not a real effect on residual flux, a strong influence of floating structures has been identified. The main impact is the drastic reduction of microscale eddy structures in the inner part of the marina (Fig. 7B). The velocity intensity has decreased by more than $30 \%$ in the whole marina whereas the NE basin displays a maximum attenuation of $65 \%$ (Table 3). This reduction is compensated by a slight velocity increase in the channel entrance during peak flood and ebb flows. These significant differences between the model 
with and without floating structures raised questions about the resuspension and siltation of the marina. Therefore, it appears relevant that a highly populated port should consider the effect of floating docks and boat moorings in any hydro sedimentary modeling study.

Further research needs to be carried out to characterize the influence of floating structures on wind stress. Indeed, the effect of wind is decreased by floating structures and that could have a significant impact on water agitation and hydrodynamics in the marina. The results show that the influence of wind, in terms of velocity intensity, is weaker with the presence of floating structures. The floating structures naturally decrease the wind effect by "protecting" the surface. As both the influence of wind and implementation of floating structures in the model mainly concerns the surface layers, our methodology also considers the wind decrease effect on the marina.

It is also important to consider some limitations of this study. First, we do not explicitly represent floating bodies as obstacles in the flow field. We considered floating structures only in the momentum equation while in reality they also affect the depth-integrated continuity equation. This simplification could result in an underprediction of current velocity between floating structures, as there is no contraction of the hydraulic section. Then, we do not consider the motion and dynamic forces of the floating structures. In our methodology, we do not model these effects, but we are trying to estimate the global effect of floating bodies at the scale of the entire marina. It is also important to note that our method is sensitive to the number of vertical sigma layers used in the study as well as the number of layers involved in the representation of floating structures.

\section{Impact of floating structures on eddy generation}

Even with the implementation of floating structures, transient small-scale eddies are generated in the inner part of the marina from the flood beginning until the ebb (Fig. 7A, 7B, 7C and 7D). This behavior is the result of tidally driven flow separation at the channel entrance that ensures eddy development behind the quays. It is a wellknown phenomenon that has been easily reproduced by barotropic numerical models (Pingree and Maddock, 1977; Imasato, 1983; Signell and Geyer, 1991). These are considered topographic eddies (Babu et al., 2005; Vethamony et al., 2005). The geometry of the marina leads to a considerable difference in terms of eddy structure intensity between flood and ebb tide. Whereas ebb tide is characterized by the absence of eddies, the flood time displays eddies of basin size. Depending on tidal and wind forcing, the number and size varies from between 2 and 3 eddies in the W basin, to 3 to 5 in the SW basin and 1 to 3 in the NE basin (Fig. 7). The number and size are dependent on hydrodynamic conditions, the geometry of the marina and its bathymetry (presenting strong lateral gradients due to recurring dredging). Nevertheless, the presence of floating structures substantially reduces their action and 
intensity by concentrating flow at the channel access. Although the natural generation of eddies during the flood is conserved, their presence leads to a channeling of the flow that also has an impact on residual circulation.

\section{The role of residual circulation in particle residence time}

According to Babu et al. (2005) tide-topography interaction is the main mechanism generating residual eddies because topographic variations in the eddy region slow tidal wave propagation, inducing a phase shift. In La Rochelle Marina, residual flow computed from the averaging of depth-averaged currents over 5 tidal cycles presents microscale eddies. In terms of size and location, these eddies correspond to the topographic eddies created by tide-topography interaction during the flood discussed earlier. Their intensity is weaker, and it can reach a maximum of $0.2 \mathrm{~m} . \mathrm{s}^{-1}$ intensity in the NE basin, during spring tides.

Our results show that the presence of both average $7.5 \mathrm{~m} . \mathrm{s}^{-1}$ wind and floating structures is sufficient to significantly affect the shape and intensity of residual eddies. Whereas wind stretches the tide-induced eddies in its direction of propagation, the floating structures focus the residual flow on the channel entrances. The wind and floating structures alter the residual circulation of the marina differently; although the former modifies the RFs substantially at the entrance section, the latter reorganizes residual flow without really modifying RFs.

Vethamony et al. (2005) suggested the contribution of residual eddies to the net transport of material from the system and their potential role in the transport of pollutants. Although Wolanski and King (1990) presented enhancement by eddies by flushing process, long term-transport is altered by the presence of residual eddies, reducing the flushing rate (Babu et al., 2005). Thus, questions are raised about particle residence time and more generally about water quality. Floating structures could influence significantly the residence time of particles or discharged material in the marina. To address this question, further research is conducted to characterize water mass exchanges under the influence of wind and tide forcings, with the presence of floating structures.

\section{Conclusion}

This paper presents the influence of floating structures on the hydrodynamics of a highly populated marina. Assessment of the main driving mechanisms, tide and wind forcings, has been conducted and an original implementation of floating structures was conducted and discussed. In situ velocity measurements have shown model overestimation without floating structures in the inner parts of the marina. Conversely, the implementation of floating bodies has permitted one to fit observations and highlight their strong influence on the attenuation of current. This reduction in intensity is mainly compensated by a slight increase in the access channels during peak flow. Furthermore, the residual circulation is also impacted by their presence; the residual eddies naturally formed 
in the marina by tide-topography interaction are strongly attenuated. As tidally induced eddies play an important role in the dispersion of matter (Yanagi, 1974), they could decrease this dispersion as well as the resuspension. Thus, questions are raised about water quality, siltation and more extensively, dredging maintenance strategy.

Even if the area is under the influence of a macrotidal regime, the role of wind is also undeniable; although significant during spring tides, its influence can be dominant during neap tides, approaching $50 \%$ in terms of mean velocity. Wind also affects the residual circulation, by modifying the size and form of eddies and by reversing the RFs. To assess the relative importance of the different processes a study is being conducted. Its objective is to characterize particle residence time under tidal and wind forcing with the presence of floating structures.

\section{Data Availability Statement}

Some observed and simulated data generated and used during the study are available from the corresponding author by request (simulated and observed water level obtained in 2017 and currents obtained in 2018).

The code used during this study is available in a repository online in accordance with funder data retention policies (http://www.opentelemac.org/).

Some data used during the study are proprietary or confidential in nature and may only be provided with restrictions (CREOCEAN is the owner of the observed currents data obtained in 2014. To acquire these data and to know the restrictions associated, you should ask directly with CREOCEAN). Some data used during the study were provided by a third party (Atmospheric data provided by NCEP, offshore water levels provided by SHOM, bathymetric data provided by SHOM without restrictions).

\section{Acknowledgements}

This work was funded by Région Nouvelle-Aquitaine, La Rochelle Marina and the CPER ("Contrat Plan Etat Région”) DYPOMAR. The developing team of TELEMAC is warmly acknowledged for making its code available and providing useful discussion. Water level data originate from the REFMAR network (SHOM) and the atmospheric forcing was provided by the National Center for Environmental Prediction (NCEP). We also thank CNRS and the Université de la Rochelle for their support and Xavier Bertin for the review and helpful advice. 


\section{References}

Babu, M. T., Vethamony, P., Desa, E. (2005). "Modelling tide-driven currents and residual eddies in the Gulf of Kachchh and their seasonal variability: A marine environmental planning perspective." Ecological Modelling. 184, 299-312.

Baker C. J. (1980). “The turbulent horseshoe vortex.” Journal of Wind Engineering \& Industrial Aerodynamics. $6,9-23$.

Bedri, Z., Bruen, M., Dowley, A. (2011) “A three-dimensional hydrod-environmental model of Dublin bay.” Environ Model Assess. 16, 369-384.

Bertin, X., Bruneau, N., Breilh, J. F., Fortunato, A. B., Karpytchev, M. (2012). "Importance of wave age and resonance in storm surges: the case Xynthia, Bay of Biscay.” Ocean Modelling. 42, 16-30.

Bertin, X., Li, K., Roland, A., Bidlot, J.-R. (2015). "The contribution of short-waves in storm surges: Two case studies in the Bay of Biscay." Continental Shelf Research. 96, 1-15.

Chaumillon, E. and Weber, N. (2006). "Spatial variability of modern incised valleys on the French Atlantic coast: Comparison between the Charente (Pertuis d'Antioche) and the Lay-Sèvre (Pertuis Breton) incisedvalleys." In : SEPM Special publication, 85, Incised Valleys in Time and Space, edited by: Robert W. Dalrymple, Dale A. Leckie, and Roderick W. Tillman. 57-85.

Cornett, A., Durand, N., Serrer, M. (2010). “3-D Modelling and assessment of tidal currents resources in the Bay of Fundy, Canada." Proceedings of the 3rd International Conference on Ocean Energy in Bilbao.

Cutroneo, L., Ferretti, G., Scafidi, D., Ardizzone, GD., Vagge, G., Capello, M. (2017). “Current observations from a looking down vertical V-ADCP: interaction with winds and tide. The case of Giglio Island (Tyrrhenian Sea, Italy).” Oceanologia. 59(2), 139-152.

Deng, Z.-Q., Bengtsson, L., Singh, V. P., Adrian, D. D. (2002) "Longitudinal dispersion coefficient in singlechannel streams.” Journal of Hydraulic Engineering. 128, 901-916

Dilorenzo, J. L. (1988). “The overtide and filtering response of small inlet/bay systems.

Hydrodynamics and sediment dynamics of tidal inlets." Lecture notes on Coastal and Estuarine Studies. 29, 2453.

Dodet, G., Bertin, X., Taborda, R. (2010). "Wave climate variability in the North-East Atlantic Ocean over the last six decades." Ocean Modelling. 31(3-4), 120-131.

Donea, J. (1982). "Arbitrary Lagrangian-Eulerian finite element methods." Computer methods in applied mechanics and engineering. 33, 473-516. 
Drobyshevski, Y. (2004). "Hydrodynamic coefficients of a two-dimensional, truncated rectangular floating structure in shallow water." Ocean Engineering. 31, 305-341.

Falconer, R. A. (1992). Flow and water quality modelling in coastal and inland water. Journal of Hydraulic Research. 30, 437-452.

Flather, R.A. (1976). Results from a storm surge prediction model of the north-west European continental shelf for April, November and December, 1973 Wormley, UK. Institute of Oceanographic Sciences 37pp.

Ghadimi, P., Maleki, F. S., Chekab, M. A. F. (2014). Hydrodynamic study of a fixed pontoon structure under wave load with different Reynolds numbers. Journal of Marina science and technology. 22, 186-195.

Grifoll, M., Fontán A., Ferrer, L., Mader J., González, M., Espino, M. (2009). “3D hydrodynamic characterization of a meso-tidal harbour: The case of Bilbao harbour (northern Spain)". Coastal Engineering. 56, 907-918.

Guo, W., Song, D., Wang, X, H., Ding, P., Ge, J. (2016). “Contributions of different tidal interactions to fortnightly variation in tidal duration asymmetry." Journal of Geophysical Research. 121, 5980-5994.

Hervouet, J.-M. (2000). “TELEMAC modelling system: an overview” Hydrological Processes. 14, 2209-2210. Hervouet, J.-M. (2007). Hydrodynamics of Free Surface Flows: Modelling With the Finite Element Method. Wiley, $360 \mathrm{pp}$.

Hervouet J.-M., Razafindrakoto R., Villaret V. (2011). "Dealing with dryzones in free surface flows: a new class of advection schemes." Proceedings of the AIRH congress.

Hervouet, J.-M. (2015). "Distributive advection schemes and dry zones, new solutions.” Proceedings of the xxiid TELEMAC-MASCARET User Conference. 259-265.

Imasato, N. (1983). “What is tide-induced residual current?” Journal of Physical Oceanography. 13, $1307-1317$. Kopmann, R. and Markofsky, M. (2000). "Three-dimensional water quality modelling with TELEMAC-3D." Hydrological Processes. 14, 2279-2292.

Le Cann, B. (1990). "Barotropic tidal dynamics of the Bay of Biscay shelf: observations, numerical modelling and physical interpretation." Continental Shelf Research. 10 (8), 723-758.

Le Hir, P., Kervella, S., Stanisère, J,-Y, Robert, S. (2010). "Modelling erosion, deposition and sediment fluxes in the Marennes-Oleron Bay: validation and discussion on uncertainties assessment.” ISOBAY 12, XII International Symposium on Oceanography of the Bay of Biscay: Global changes in the Bay of Biscay. 3-6 May 2010, Brest, France.

Li, D., Panchang, V., Tang Z., Demirbilek Z., Ramsden, J. (2005). "Evaluation of an approximate method for incorporating floating docks in harbour wave prediction models." NRC Research Press Web. 32, 1082-1092. 
Ligier, P.-L., Söderström A., Bohlin, C., Lier, O. (2016). "Modelling complex vertical structures with TELEMAC3D.” Proceedings of the xxiiird TELEMAC-MASCARET User Conference. 259-265.

Martinuzzi, R., and Tropea, C. (1993). "The flow around surface-mounted, prismatic obstacles placed in a fully developed channel flow." Journal of Fluids Engineering. 115, 85-92.

Murphy, E., Deiber, M., Perrin, S. (2012). "Shear-driven flushing of micro-tidal marinas.” Coastal Engineering Proceedings. 33, 1-15.

Nicolle, A. (2006). Modélisation des marées et des surcotes dans les Pertuis Charentais, PhD Thesis, La Rochelle, France.

Nece, R. E. (1984). "Planform effects on tidal flushing of marinas." Journal of Waterway, Port, Coastal, and Engineering. 110, 251-269.

Nece, R.E., and Richey, E.P. (1972). "Flushing characteristics of small-boat marinas.” Coastal Engineering. 111, 2499-2512.

Nicolle, A. and Karpytchev, M. (2007). "Evidence for spatially variable friction from tidal amplification and asymmetry in the Pertuis Breton (France).” Continental Shelf Research. 27, 2346-2356.

Pairaud, I., Lyard, L., Auclair, F., Letellier, T., Marsaleix, P. (2008). "Dynamics of the semi-diurnal and quarterdiurnal internal tides in the Bay of Biscay. Part 1: barotropic tides.” Cont Shelf Res. 28, 1294-1315.

Pingree, R. D. and L. Maddock. (1977). “Tidal residuals in the English Channel.” Journal of the marine Biological Association United Kingdom. 57, 339-354.

Poirier, C., Sauriau, P.-G., Chaumillon, E., Bertin, X. (2010). "Influence of hydro-sedimentary factors on mollusc death assemblages in a temperate mixed tide-and-wave dominated coastal environment: Implications for the fossil record." Continental Shelf Research. 30 (17), 1876-1890.

Sanchez-Arcilla, A., Caceres, I., Gonzalez, D., Sierra, J. P., Escutia, R. (2002). "Water renovation in harbour domains. The role of wave and wind conditions." Coastal Engineering. 1267-1278.

Signell, R.P., and Geyer, W.R. (1991). “Transient eddy formation around headlands.” Journal of Geophysical Research. 96, 2561-2575.

Sztano, O., and De Boer, P.L. (1995). "Basin dimensions and morphology as controls on amplification of tidal motions (the Early Miocene North Hungarian Bay).” Sedimentology. 42 (4), 665 - 682.

Tajali Z., Shafieefar, M., Akhyani, M. (2008). "Hydrodynamic analysis of multi-body floating piers under wave action.” Ocean Engineering. 38, 1925-1933. 
Toublanc, F., Brenon, I., Coulombier, T., Le Moine, O. (2015). «Fortnightly tidal asymmetry inversions and perspectives on sediment dynamics in a macrotidal estuary (Charente, France)." Continental Shelf Research. 94, 42-54.

Tsay, T.-K., Liu, P. L.-F. (1983). “A finite element model for wave refraction and diffraction.” Applied Ocean Research. 5, 30-37.

Van Rijn, L. C. (1984) “Sediment Transport, Part III: Bed Forms and Alluvial Roughness.” Journal of Hydraulic Engineering. 110, 1733-1754.

Vethamony, P., Reddy, G.S., Babu, M.T., Desa, E., Sudheesh, K. (2005). “Tidal eddies in a semi-enclosed basin: a model study.” Marine Environmental Research. 59, 519-532.

Villaret, C., Hervouet, J.-M., Kopmann, R., Merkel, U., Davies, A. G. (2013). “Morphodynamic modelling using the Telemac finite-element system.” Computers \& Geosciences. 53, 105-113.

Weitz, M. A., Arslan, A. B., Lane, L. J. (1992) “Hydraulic roughness coefficients for native rangelands.” Journal of Irrigation and Drainage Engineering. 118, 776-790.

Winterwep, J.-C. (2005). "Reducing Harbor Siltation.” Journal of Waterway, Port, Coastal, and Ocean Engineering. 131, 258-266.

Wolanski, E., and King, B. (1990). "Flushing of Bowden Reef Lagoon, Great Barrier Reef.” Estuarine Coastal and Shelf Science. 31(6), 789-804.

Yanagi, T. (1974). "Dispersion due to the residual flow in the hydraulic model." Contributions of Geophysics Institute Kyoto University 14, 1-10.

(1)

(1)

0

1

5



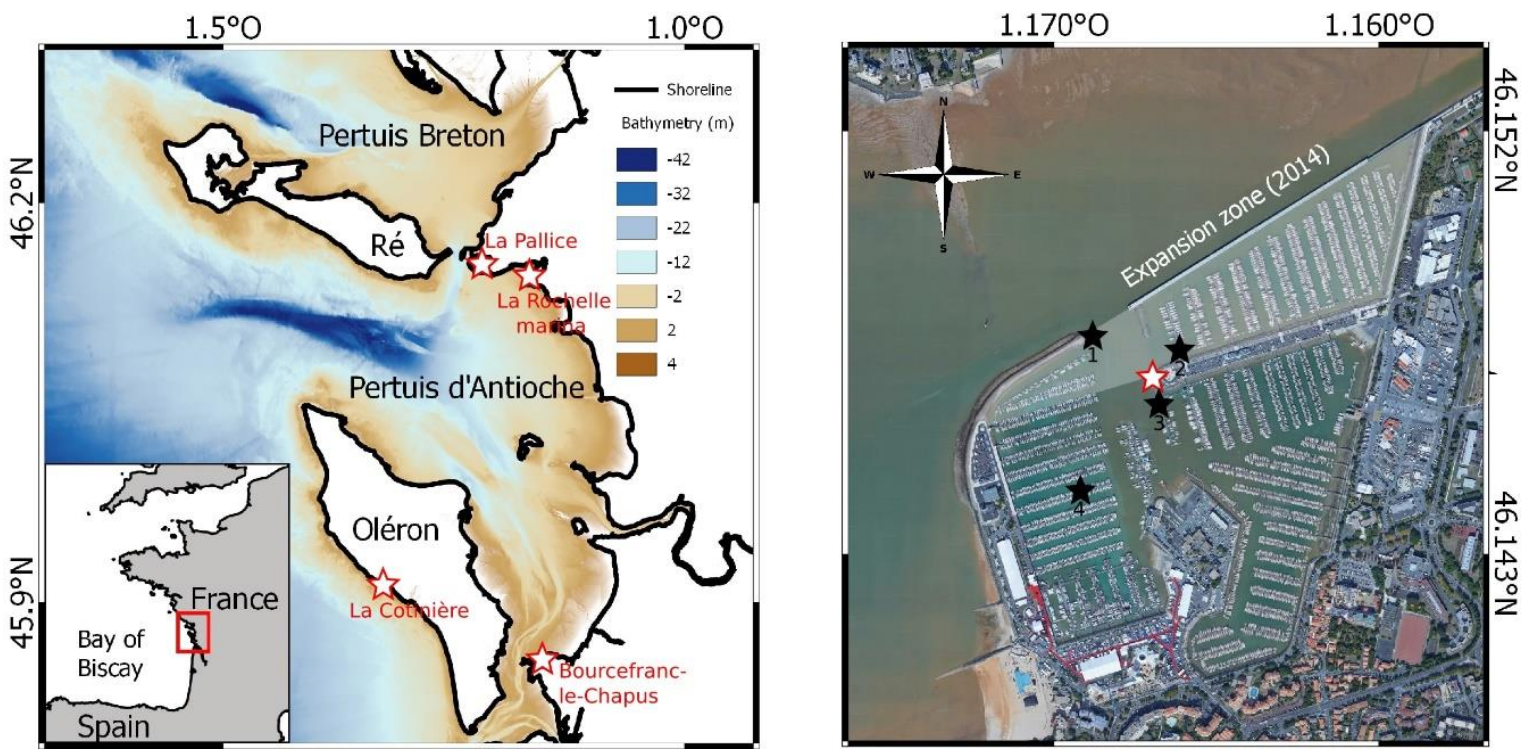

Fig. 1. Bathymetric/topographic (left) and google satellite image of La Rochelle Marina (right). Altitudes are given with respect to mean-sea-level, and white stars with red borders indicate tide gauges. The shoreline is indicated by straight bold black line in the left figure, and black stars represent ADCP moorings in the right figure.
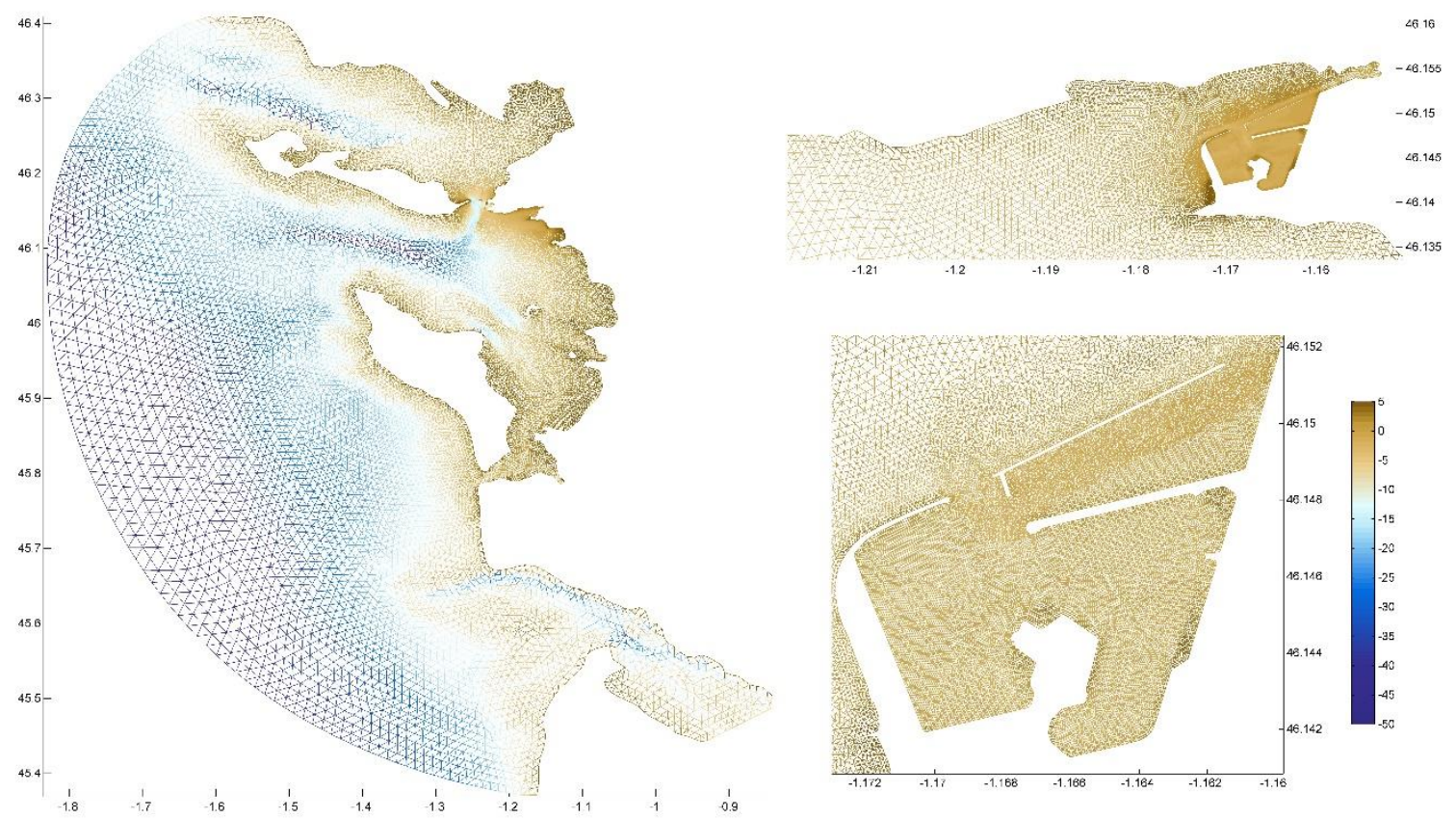

Fig. 2. Unstructured grid used in this study, implemented over the Pertuis Charentais Embayment. Colors indicate grid bathymetry ranging from 44 to 0 meters. 


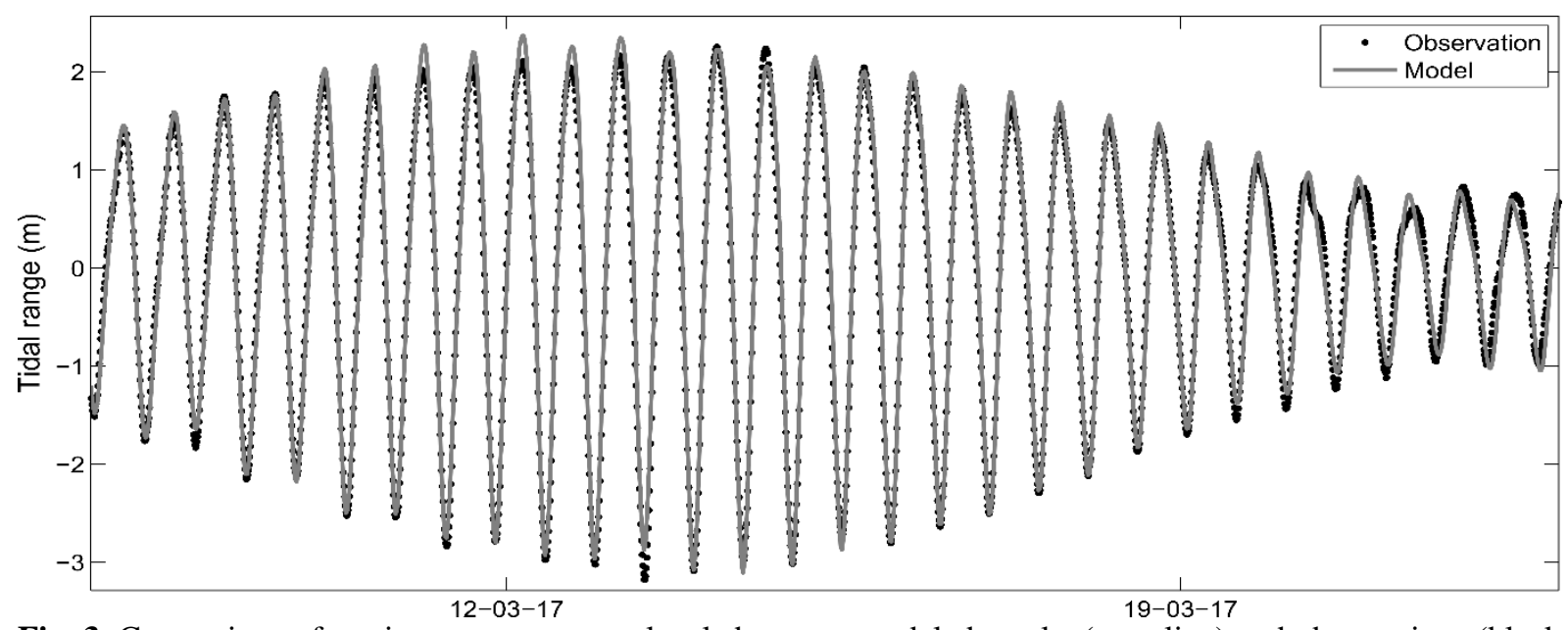

Fig. 3. Comparison of marina entrance water levels between modeled results (gray line) and observations (black circles) for 15 days including neap and spring tides.

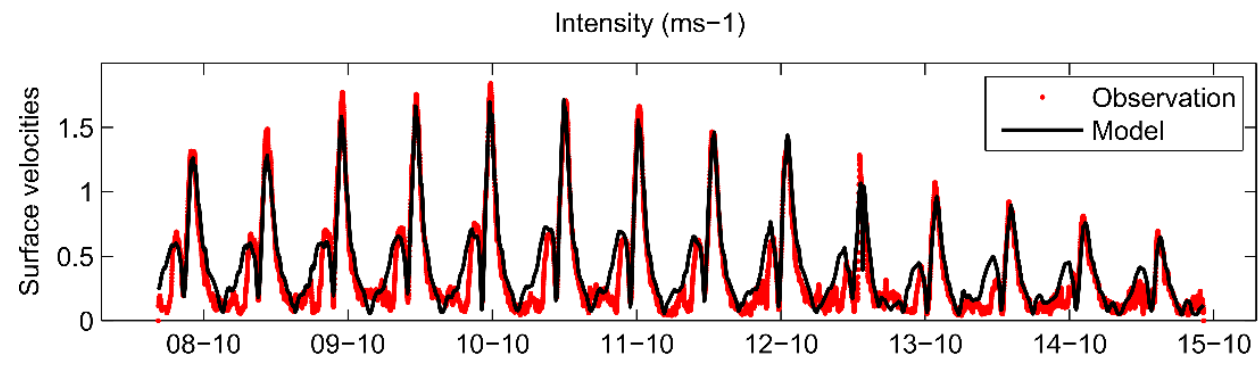

Direction (degrees)
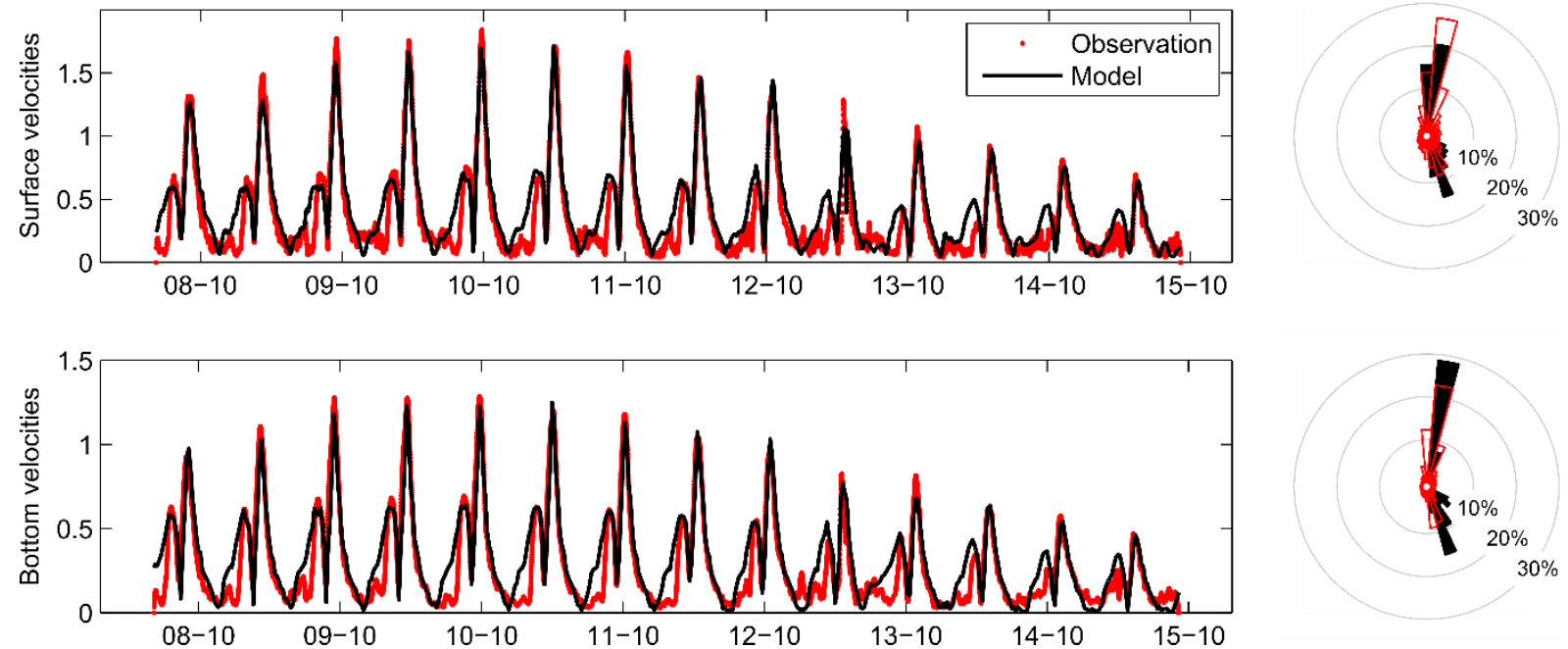

Fig. 4. Comparison of velocity at the marina entrance between numerical results (black line) and observations (red dots) for one week of spring tides in October 2014 (mean tidal range $=6$ meters). 


\section{Observations}
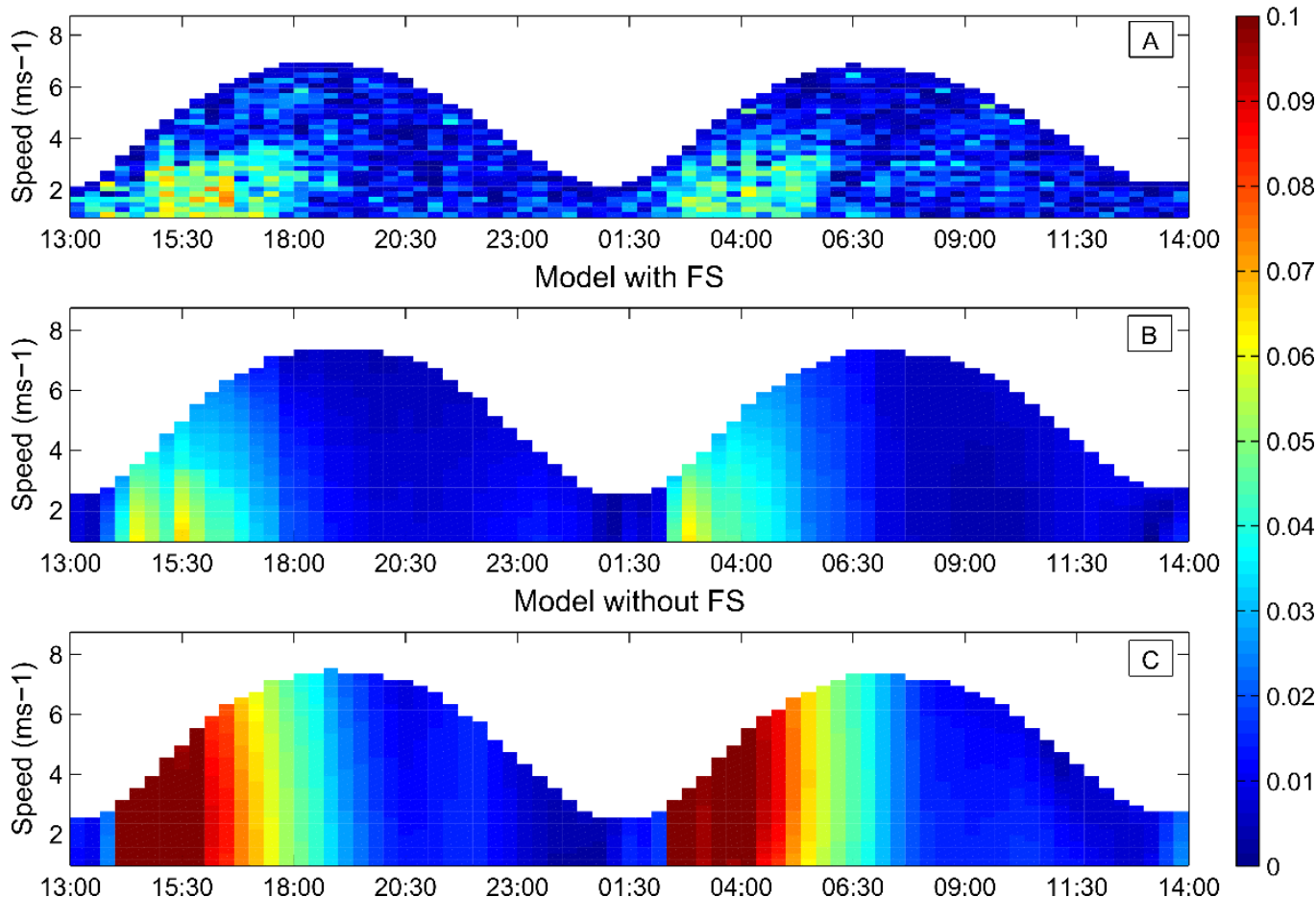

Fig. 5. Comparison of velocity intensity $\left(\mathrm{m} . \mathrm{s}^{-1}\right)$ computed with floating structures (B), without floating structures

(C) and acquired with ADCP (A) in the inner part of the western marina basin for one day in May 2018 (mean

Intensity (ms-1)
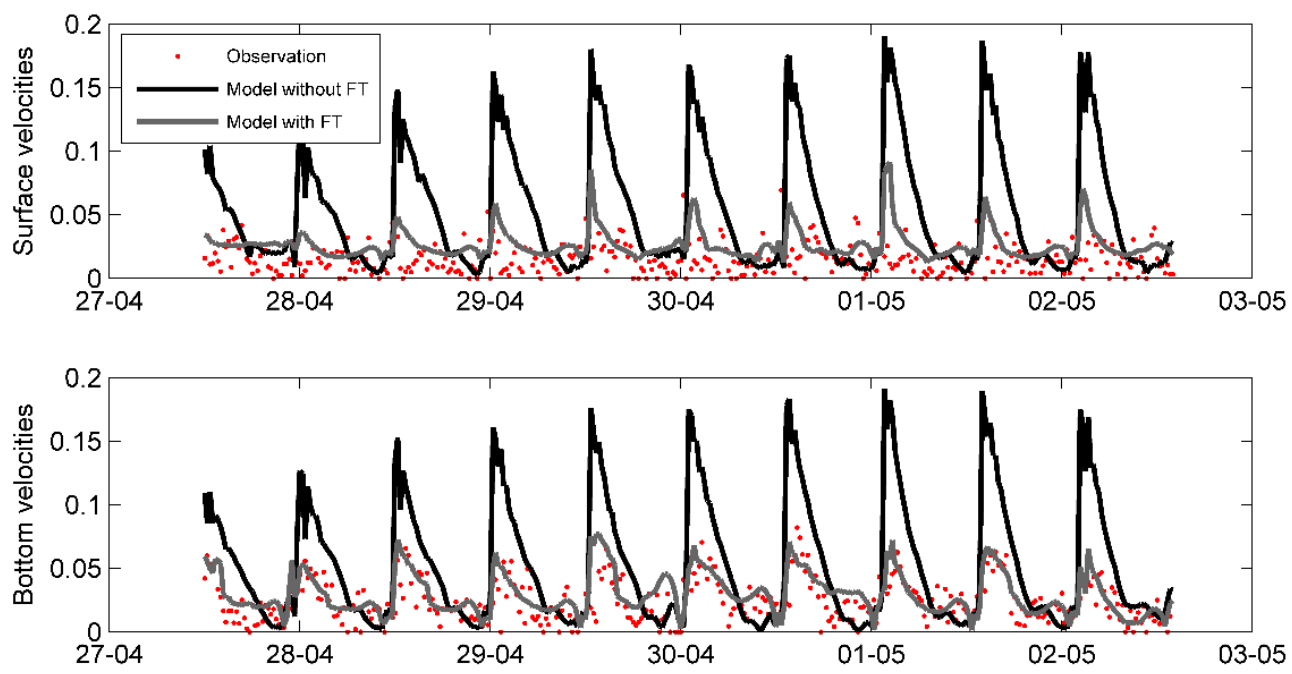

Direction (degrees)
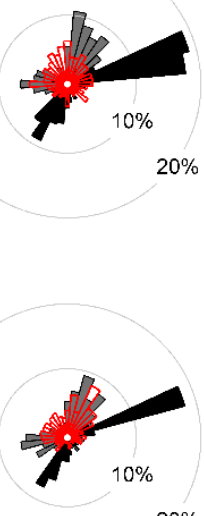

$20 \%$

Fig. 6. Comparison of velocity computed with floating structures (gray line), without floating structures (black line) and acquired with ADCP (red) inside the marina for three days in May 2018 (mean tidal range $=4$ meters).

FS corresponds to floating structures. 

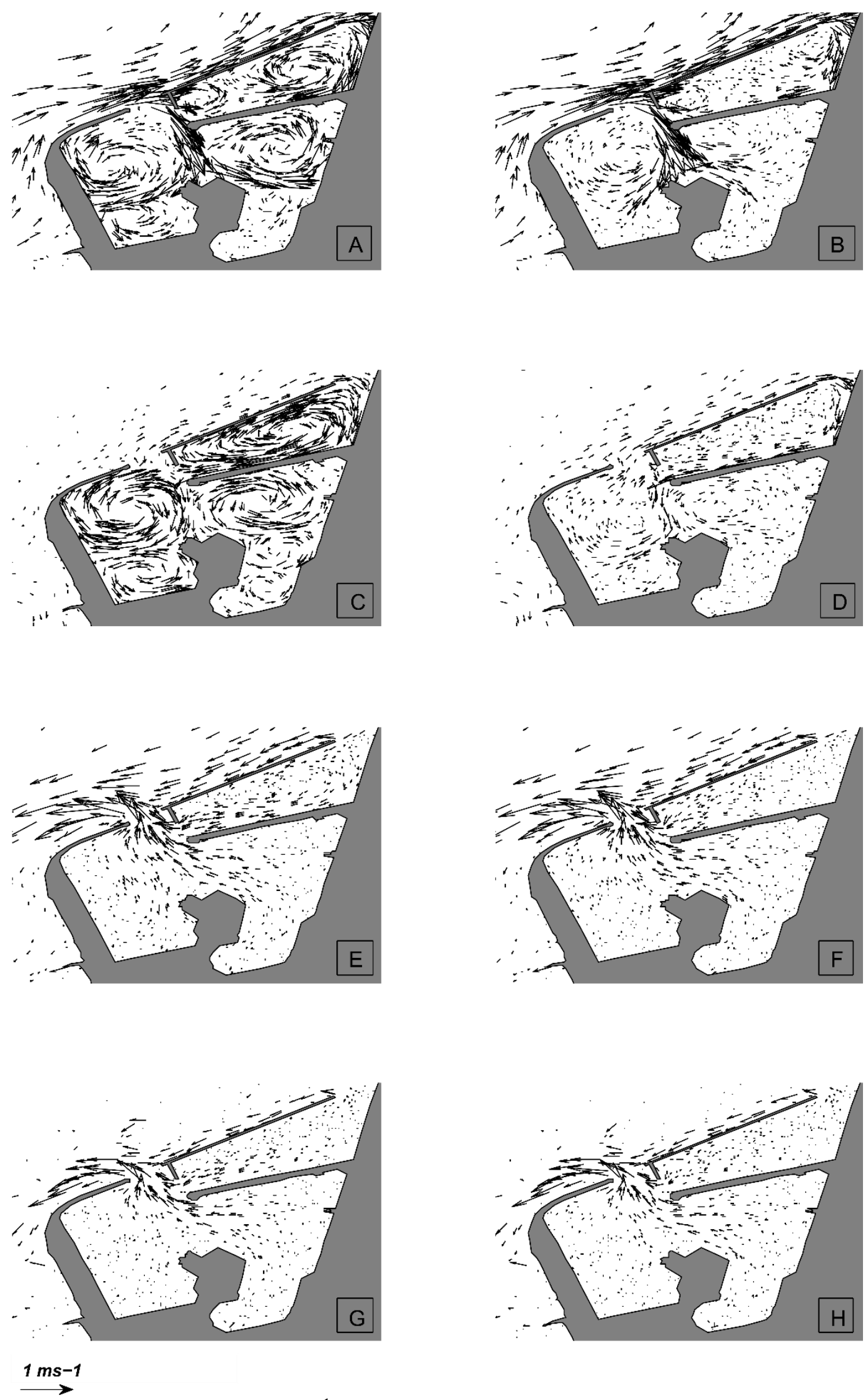

Fig. 7. Depth-averaged velocity field $\left(m \cdot s^{-1}\right)$ for simulations with (right) and without (left) floating structures. A low tide. 

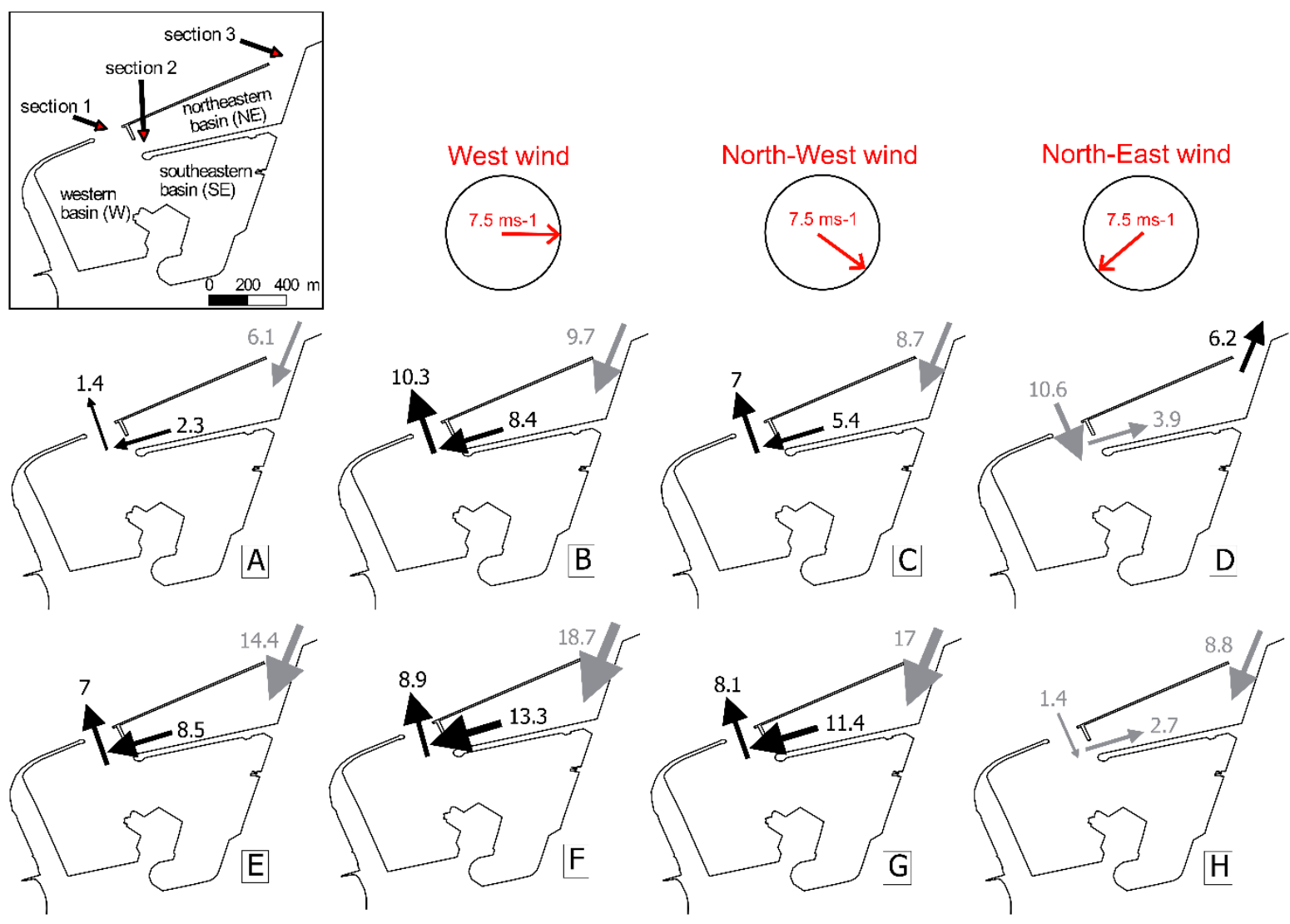

Fig. 8. Residual fluxes $\left(\mathrm{m}^{3} \cdot \mathrm{s}^{-1}\right)$ at the entrances defined in the top figure for several conditions of wind and tides.

A , B , C, D correspond to neap tide conditions and E, F, G, H correspond to spring tide conditions. A-E represent northeast winds. 
Tables

Table 1. Metrics between numerical results and measurements

\begin{tabular}{cccc}
\hline & $\begin{array}{c}\text { RMSE } \\
(\mathbf{m})\end{array}$ & $\begin{array}{c}\text { Maximum Errors } \\
(\mathbf{m})\end{array}$ & $\begin{array}{c}\text { Bias } \\
(\mathbf{m})\end{array}$ \\
\hline La Rochelle Marina & 0.17 & 0.25 & 0.08 \\
La Pallice & 0.18 & 0.30 & 0.13 \\
La Cotinière & 0.19 & 0.31 & 0.17 \\
Bourcefranc-le- & 0.19 & 0.31 & 0.11 \\
Chapus & & & \\
\hline
\end{tabular}

Measurements were taken at the several tide gauges corresponding to white stars bordered in red in Fig. 1. Metrics for La Rochelle Marina are averaged for comparison between numerical results and data from the four tide gauges deployed in the marina.

Table 2. Metrics between depth-averaged numerical results and ADCP measurements of velocity

\begin{tabular}{cccccc}
\hline & \multicolumn{3}{c}{ Intensity $\left(\mathbf{m . ~ s}^{\mathbf{- 1}}\right)$} & & \multicolumn{2}{c}{ Direction (degrees) } \\
& RMSE & Maximum Errors & Bias & RMSE & Bias \\
\hline ADCP 1 & 0.072 & 0.16 & 0.032 & 51.3 & 20.1 \\
ADCP 2 & 0.065 & 0.12 & 0.028 & 46.1 & 11.2 \\
ADCP 3 & 0.069 & 0.17 & 0.034 & 62.3 & -68.4 \\
ADCP 4 & 0.064 & 0.10 & 0.091 & 129.7 & -12.5 \\
(without FS) & & 0.02 & 0.005 & 75.8 & \\
ADCP 4 & 0.012 & & & & \\
(with FS) & & & & & \\
\hline
\end{tabular}

Note: FS = floating structures

ADCP measurements were acquired during three spring tide days in October 2014 (ADCP 1, 2 and 3), and in May 2018 (ADCP 4).

Table 3. Depth averaged velocity computed in the marina for spring and neap tides.

\begin{tabular}{ccc}
\hline & $\begin{array}{c}\text { Spring tides } \\
\left(\boldsymbol{m} . \boldsymbol{s}^{-\mathbf{1}}\right)\end{array}$ & $\begin{array}{c}\text { Neap tides } \\
\left(\boldsymbol{m} . \boldsymbol{s}^{-\mathbf{1}}\right)\end{array}$ \\
\hline WB & $0.50(0.76)-0.81(0.80)-1.17(1.50)$ & $0.12(0.14)-0.15(0.11)-0.27(0.34)$ \\
SEB & $0.61(0.74)-0.94(0.81)-1.45(1.59)$ & $0.13(0.14)-0.23(0.23)-0.37(0.43)$ \\
NEB & $0.25(0.73)-0.39(1.01)-0.73(1.56)$ & $0.07(0.08)-0.09(0.10)-0.38(0.45)$ \\
CE & $0.90(0.89)-1.19(1.16)-1.68(1.68)$ & $0.23(0.23)-0.19(0.17)-0.59(0.58)$ \\
Total Marina & $0.56(0.75)-1.19(1.16)-1.68(1.68)$ & $0.14(0.18)-0.23(0.23)-0.59(0.58)$ \\
\hline
\end{tabular}
Note: WB = western basin; SEB = southeastern basin; NEB = northeastern basin; $\mathrm{CE}=$ channel entrance.

Each entry corresponds to mean velocity, maximum velocity during ebb, and maximum velocity during flood, with (and without) floating structures in several parts of the marina. 
Table 4. Depth averaged velocity for several configurations of tides and wind

\begin{tabular}{|c|c|c|}
\hline & $\begin{array}{l}\text { Spring tides } \\
\quad\left(m \cdot s^{-1}\right)\end{array}$ & $\begin{array}{l}\text { Neap tides } \\
\left(m \cdot s^{-1}\right)\end{array}$ \\
\hline No wind & $0.56(0.75)$ & $0.14(0.18)$ \\
\hline $\mathrm{WW}\left(15 m \cdot s^{-1}\right)$ & $0.50(0.70)$ & $0.29(0.42)$ \\
\hline WW $\left(7.5 m \cdot s^{-1}\right)$ & $0.49(0.65)$ & $0.18(0.22)$ \\
\hline NWW $\left(7.5 m . s^{-1}\right)$ & $0.44(0.60)$ & $0.20(0.22)$ \\
\hline $\operatorname{NEW}\left(7.5 m \cdot s^{-1}\right)$ & $0.42(0.56)$ & $0.16(0.19)$ \\
\hline $\mathrm{SW}\left(7.5 m . s^{-1}\right)$ & $0.57(0.64)$ & $0.21(0.25)$ \\
\hline
\end{tabular}

636 Note: $\mathrm{WW}=$ west wind; NW = north-west wind; NEW = north-east wind; $\mathrm{SW}=$ south wind.

637 Each entry corresponds to the total mean marina velocity computed over 5 tidal cycles for 6 specific cases with 638 (and without) floating structures: without wind, with strong $15 \mathrm{~m} . \mathrm{s}^{-1} \mathrm{WW}$ (typical storm wind during winter), 639 and four with a $7.5 \mathrm{~m} . \mathrm{s}^{-1}$ wind. 